\title{
Capacitive Welding of SAE 10B22 Steel with SAE 1045, DOMEX 700MC and DOCOL DP 1000 Steels
}

\author{
Roger Navarro Verástegui ${ }^{1}$, João Renato Fronza Spohr ${ }^{2}$, Camila Pereira Lisboa ${ }^{3}$ and Richard Thomas Lermen ${ }^{4}$ (D) \\ ${ }^{1}$ Universidade Tecnológica Federal do Paraná - UTFPR, Departamento Acadêmico de Engenharia Mecânica, Ponta Grossa, PR, Brasil. \\ ${ }^{2}$ Faculdade Horizontina - FAHOR, Departamento de Engenharia Mecânica, Horizontina, RS, Brasil. \\ ${ }^{3}$ Faculdade Meridional - IMED, Escola Politécnica, Departamento de Engenharia Mecânica, Passo Fundo, RS, Brasil. \\ ${ }^{4}$ Faculdade Meridional - IMED, Escola Politécnica, Programa de Pós-graduação em Engenharia Civil, IMED, Passo Fundo, RS, Brasil.
}

Como citar: Verástegui RN, Spohr JRF, Lisboa CP, Lermen RT. Capacitive welding of SAE 10B22 steel with SAE 1045, DOMEX 700MC and DOCOL DP 1000 steels. Soldagem \& Inspeção. 2021;26:e2605. https://doi.org/10.1590/0104-9224/SI26.05

\begin{abstract}
The use of welding of dissimilar materials in the manufacture of different products, both in automobile and civil construction industry, is necessary and understanding the factors that may interfere in the quality of the final product is important for its correct development. So, the main aim of this work was to perform the capacitive welding of different steels, evaluating the effect of different energies on the microstructural evolution and hardness profiles of the welded region. Three different steels were used as base materials (SAE 1045 carbon steel, DOMEX 700MC steel, and DOCOL DP 1000 steel), which were attached to a SAE 10B22 steel pin. To weld, the steels, a bank of capacitors was used, which allows different energies. The characterization of the materials was carried out through hardness verification and metallographic characterization tests. The results show that the capacitive discharge welding process generates a heataffected zone (HAZ) of short extension, regardless of the type of steel and the average welding energy. For the three types of steel that were used and for the different average welding energies, the microstructure formed in the HAZ was martensite.
\end{abstract}

Key-words: Capacitive welding; Cooling rate; Hardness; Microstructure.

\section{Introduction}

Parallel to the investments and ambitions of industrial organizations, the continuous technological advancement by launching opportunities in the areas of development and manufacturing is evident. The welding process by capacitive discharge is recent when compared to the other conventional processes of welding. This process is characterized by the high speed of completion, yielding little time for melting of the material and, consequently, a high rate of cooling in the welded region. Also, capacitive welding allows welding dissimilar materials with high weld quality [1-3].

Thus, some gaps and information regarding welding performed by the capacitive discharge process need to be investigated, mainly issues related to the region affected by the heat of the weld, the hardness, and the microstructure formed, responses that may characterize a weld joint that is acceptable or not for a particular functional application. For example, if the welded region is only exposed to wear, it is necessary to increase the hardness of this region, or if the welded region is subject to stress and impact, a lower level of hardness is indicated in the joint [4-10].

Capacitive discharge welding is an innovative manufacturing process with a high potential for automation and robotization. It also allows the welded joint of components with different chemical and mechanical properties, that is, the joint of dissimilar materials. In the industry, capacitive discharge welding is used, mainly, in the welding of pins and fasteners. Welding of pins in tubes of heat exchangers in the boiler industry; welding of fasteners in metal structures, without the need of drilling the structure; in the electrical and automotive construction, it has been replacing screw connections and fastening parts [11]. In this process, the capacitive discharge is very fast, and the operating time is in the order of milliseconds, which provides a high cooling rate and consequently a narrow heat affected zone (HAZ). Due to the high cooling rates, different microstructures may arise [8-10]. These microstructural evolutions generate significant changes in the mechanical properties of the materials

When a specific welding process is carried out, the structural changes formed in the HAZ need to be investigated. The analyses of the microstructures formed contribute preventing stress concentrations and possible weld joint-related defects. The microstructure and hardness formed will indicate factors of brittleness, tenacity, and functionality of the welded joint [12-14].

$\mathrm{DOCOL}^{\circledR}$ and DOMEX ${ }^{\circledR}$ steels are micro-alloyed steels with high mechanical strength. This is due to great control in the addition of manganese and silicon. There is still the addition of Niobium, Titanium, and Vanadium. The total number of alloying elements is reduced when compared to conventional bonded steels, so that both the carbon level and the low carbon equivalent 
level can be maintained and thus facilitate welding by conventional processes [15]. Equation 1 of carbon equivalent $\left(C_{e q}\right)$ can be seen below, as recommended by AWS D1.1 / D1.1M [16].

$C_{e q}=C+\frac{M n}{6}+\frac{C r+M o+V}{5}+\frac{C u+N i}{15}$

Concerning the welding, the steels cited above can be welded in an acceptable manner by most processes and they are not susceptible to solidification cracking and the hydrogen-induced cracking (HIC) [15].

According to Lisiecka and Lisiecka [17], who analyzed the welding of DOMEX ${ }^{\circledR} 960$ steel, this kind of steel had 0.343 carbon equivalent. The cooling time was calculated as something between $800{ }^{\circ} \mathrm{C}$ and $500{ }^{\circ} \mathrm{C}\left(\mathrm{t}_{8 / 5}-\right.$ this range is analyzed as it is the most critical for welding) and time values between 0.6 seconds and 1.3 seconds were found, which are lower values than the ones recommended for steels similar to these ones, as in the case of WELDOX ${ }^{\circledR}$ (values indicated: $t_{8 / 5}$ between 5 seconds and 15 seconds). Nevertheless, with a high cooling rate, the tests indicated good values for hardness and tensile strength, otherwise, avoiding the formation of a fragile structure [15]. These times are related to the Continuous Cooling Transformation (CCT) diagrams that relate the cooling time between temperatures from $800^{\circ} \mathrm{C}$ to $500^{\circ} \mathrm{C}$ and the probable microstructure. An example is shown in Figure 1, in which it can be seen the SAE 1045 steel diagram and the relationship with the cooling time $\left(\Delta \mathrm{t}_{8 / 5}\right)$ with an expected microstructure [18]. With this it's possible verifying if the cooling time between $800^{\circ} \mathrm{C}$ and $500{ }^{\circ} \mathrm{C}\left(\Delta \mathrm{t}_{8 / 5}\right)$ is short or long to form the fragile structure. For this steel, to avoid martensite the time $\left(\Delta \mathrm{t}_{8 / 5}\right)$ is approximately 3.5 seconds.

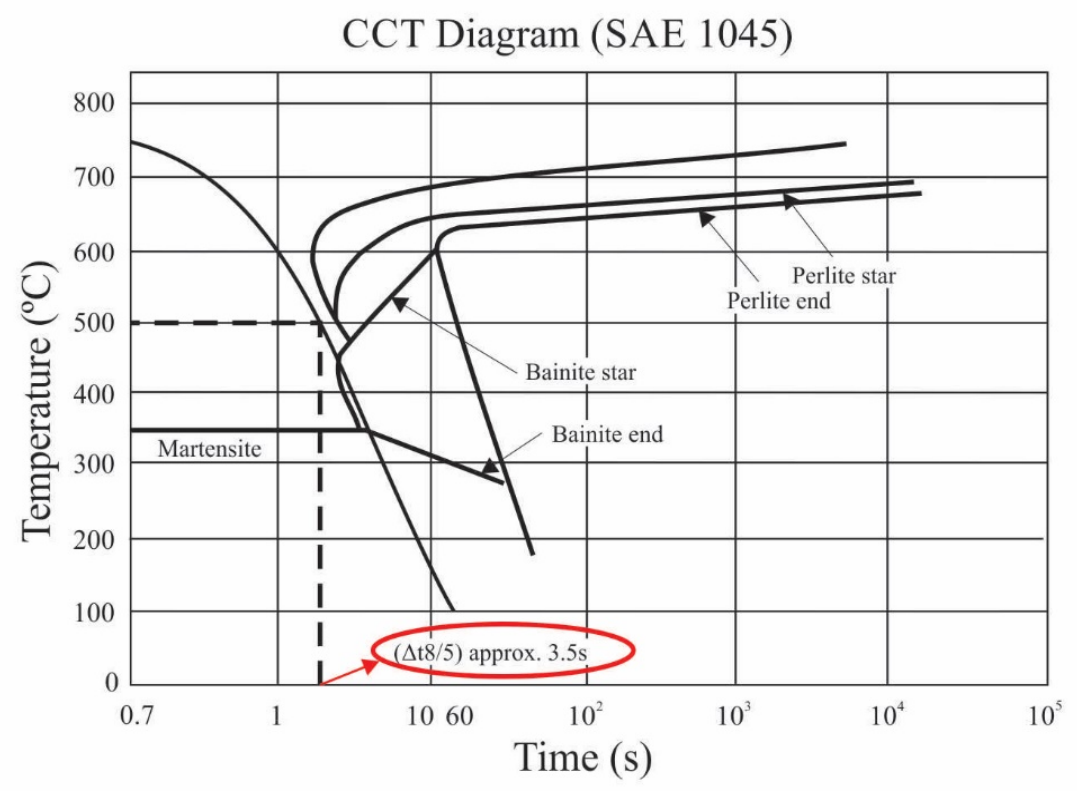

Figure 1. CCT diagram for SAE 1045. [adap. 18]

In the case of $\mathrm{DOCOL}^{\circledR}$ steel, Górka [19] performed an analysis with a $0.39 \%$ carbon equivalent steel. In the weld region the joints are characterized by the presence of martensitic structure, varying only in the size of the martensite needle, depending on the amount of energy supplied. The higher the welding energy, the greater the size of the martensite needles (greater hardness), thus increasing the heat affected zone (HAZ). However, in the HAZ, there was a decrease in hardness due to the tempering caused during welding. The study indicates that in order to reduce martensite needles (reduce hardness) and reduce the HAZ, the lowest possible welding energy should be used. The folding test showed a low ductility of the welded joint, however, the tensile strength, one of the main properties of these steels, remained similar to that of the base metal, when the lowest welding energy was used, showing that high welding energies may render welding that is unfeasible with this type of steel [15].

In this work, a device for capacitive discharge welding was used to join test specimens of SAE 1045 carbon steel, DOMEX $700 \mathrm{MC}$ steel, and DOCOL DP 1000 steel. DOCOL 1000 DP steel is a biphasic steel (duplex steel, DP) whose microstructure consists of a ferritic matrix, and the second phase is the martensitic component. This structure is produced as a result of tempering intercritical temperatures. The soft matrix results in good stamping results along with a high hardness component that increases the strength of the set [15]. This was performed to show information about microstructural changes and hardness values in the affected regions of the welded joint since there are no detailed studies regarding the effect of high cooling rates from the capacitive discharge welding process on these steels. 
The present work aims at completing the capacitive welding of different materials (SAE 10B22, SAE 1045, DOMEX 700MC and DOCOL DP 1000 steels), determining the effect of different welding average energies on the cooling rate, microstructural evolution and hardness profiles of the welded region.

\section{Materials and Methods}

The materials and methods are presented in four stages: a brief description of the welding device and its characteristics, a presentation of the materials that were used, a description of the welding of the test specimens, and a characterization of the test specimens.

\subsection{Welding device}

Welding device is divided into three distinct parts: the capacitor bank, the forging device and the power supply to charge the capacitors. The welding device is designed to join test specimens made of a pin next to a given base plate. Capacitor bank of the device consists of 12 electrolytic capacitors, which operate with voltages of $80 \mathrm{~V}$ and capacitance of $10 \mathrm{mF}$. This capacitor bank allows 6 different levels of capacitance for welding, since there are six capacitor connections in parallel, that is, the welding can be carried out with the following capacitances: $5 \mathrm{mF}, 10 \mathrm{mF}, 15 \mathrm{mF}, 20 \mathrm{mF}, 25 \mathrm{mF}$ and $30 \mathrm{mF}$.

Average welding energy, considering an electrical potential difference of 160 volts (measured average value), was $64 \mathrm{~J}\left(\mathrm{E}_{1}{ }^{-}\right.$ equivalent capacitance of $5 \mathrm{mF}$ ), $128 \mathrm{~J}\left(\mathrm{E}_{2}\right.$ - equivalent capacitance of $10 \mathrm{mF}$ ), $192 \mathrm{~J}\left(\mathrm{E}_{3}\right.$ - equivalent capacitance of $\left.15 \mathrm{mF}\right), 256 \mathrm{~J}$ $\left(E_{4}\right.$ - equivalent capacitance of $20 \mathrm{mF}$ ), $320 \mathrm{~J}\left(\mathrm{E}_{5}\right.$ - equivalent capacitance of $25 \mathrm{mF}$ ) and $384 \mathrm{~J}$ ( $\mathrm{E}_{6}$ - equivalent capacitance of $30 \mathrm{mF}$ ). To determine the average welding energy, the potential energy of a capacitor was considered, which can be calculated by Equation 2.

$$
E=\frac{C \cdot U^{2}}{2}
$$

where $E$ is average welding energy, $C$ is equivalent capacitance and $U$ is electrical potential difference. In Figure 2 , the electrical circuit and schematic drawing of the experimental apparatus can be visualized.

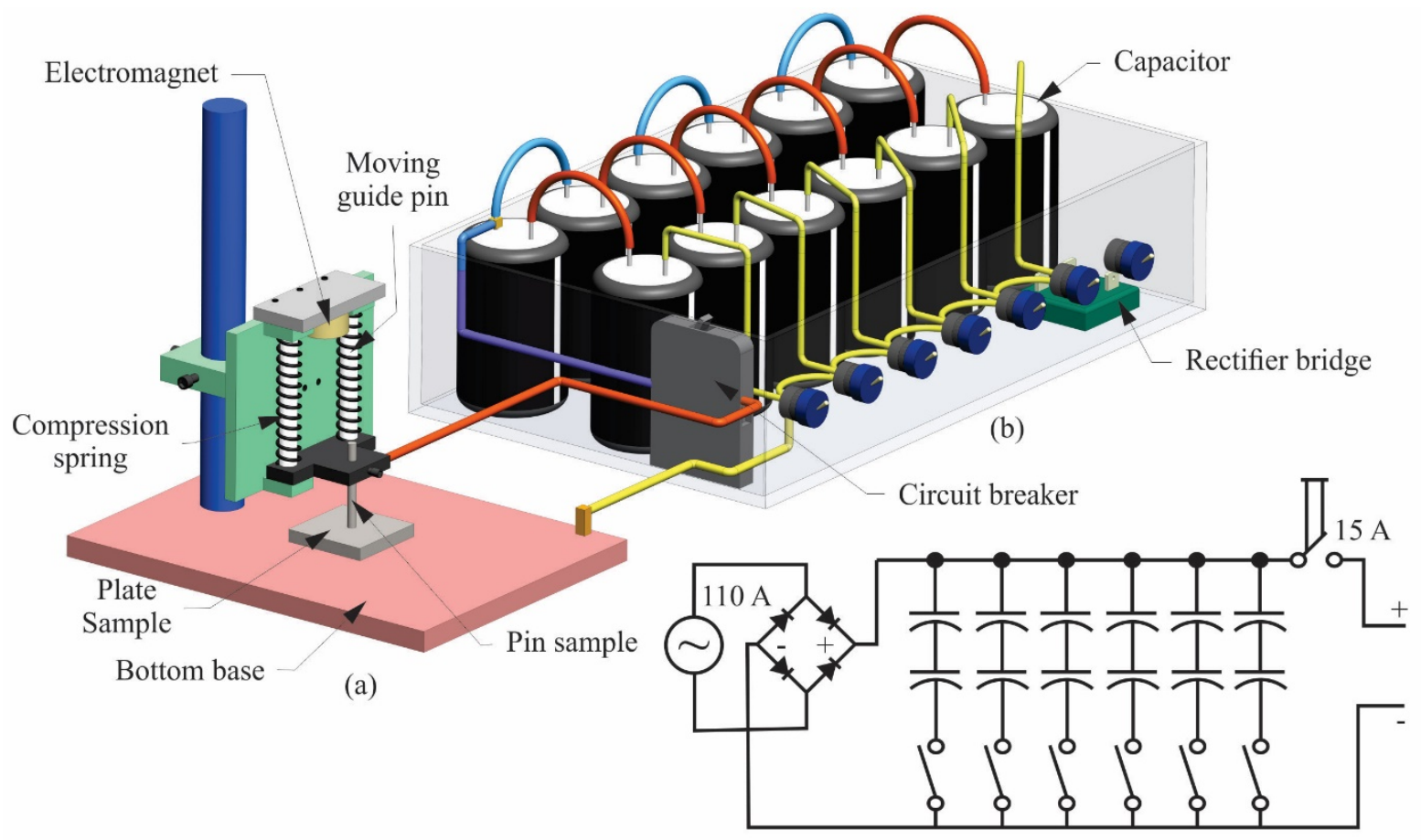

(c)

Figure 2. (a) forging device, (b) capacitor bank and (c) Capacitor bank electric circuit.

The forging device is shown in Figure 2a. The system consists of movable guide pin, trigger system (electromagnet), compression spring, acrylic sliding plate, pin fastening device, fixed guide pins and a metal bottom base. The compression spring 
provides a compression force of $30 \mathrm{~N}$. The pin-fixing device is connected to the negative pole of the capacitor bank and the bottom base, in which the welding plates are positioned and where the positive pole was connected.

The anode was always placed on the pin, so that there was not much loss of material due to the lower volume when compared to the plates. To corroborate this explanation R. D. Wilson et al. showed that there is an unequal heating rate between the cathode and the anode due mainly to the heat transfer from the plasma jet of the anode. The arc propagation is fast enough to define the capacitive discharge welding process as essentially one-dimensional. Because of this, SAE $10 \mathrm{~B} 22$ steel will less variations compared to sheets (SAE 1045, DOMEX 700MC and DOCOL DP1000), to leave the comparative analysis only between sheets and not to consider changes in the pin [20,21].

With this plasma jet, the characterization of the fusion zone was very difficult to observe, as it is a relatively small region and difficult to characterize. In this work, a large pool of fusion was not desired, was prepared for a larger HAZ for a better analysis between the materials. In this work, a large pool of fusion was not desired, it was prepared for a larger HAZ for a better analysis between the materials. The fusion zone will be disregarded due to its size and the difficulty in characterizing it. This fusion zone will always be close to the pin, because the process is essentially unidirectional.

\subsection{Characterization of materials and welding of specimens}

For the development of this study, one type of carbon steel and two copies of low alloy steel were used as base metals. Specifically, the following steels were selected: SAE 1045 carbon steel, DOMEX 700MC steel, DOCOL DP 1000 steel and SAE 10B22. Figure 3 shows the microstructures for the steels used.

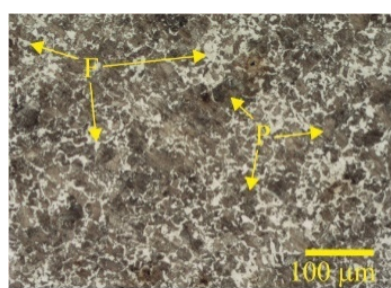

(a)

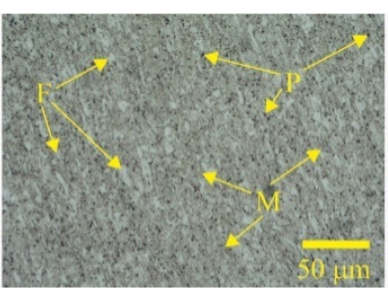

(b)

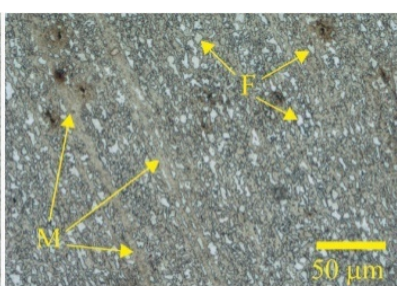

(c)

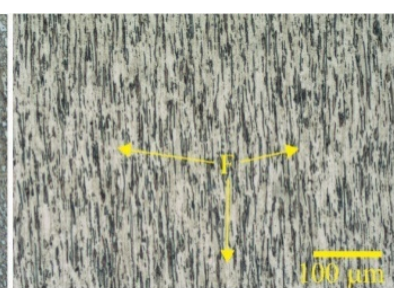

(d)

Figure 3. (a) SAE 1045 carbon steel, (b) DOMEX 700MC steel, (c) DOCOL DP 1000 steel and (d) SAE $10 B 22$.

Each of these materials is developed by steel manufacturers and their microstructures are defined due to the designation of each material. The manufacturer of DOMEX and DOCOL steels presents the steel with refined martensite. This is done by the manufacturer so that the steel reaches the desired properties (offered by the manufacturer). SAE 1045 steel was prepared with the normalizing heat treatment, so it has a ferritic/pearlitic structure.

In order to characterize the base metals, a chemical composition analysis was performed through a spark spectrometer, a metallographic characterization and a hardness verification of the materials through a hardness profile. The test specimens of the steels were manufactured and divided into small samples, forming sheet samples with approximately $25 \times 35 \mathrm{~mm}$ of edge and maintaining the original thickness of each format, i.e., for the SAE 1045 steel the original thickness was 6 mm, for DOMEX $700 \mathrm{MC}$ the thickness was $3 \mathrm{~mm}$ and for DOCOL DP 1000 steel the thickness of the sheet was $1.5 \mathrm{~mm}$. The pin used was SAE $10 \mathrm{~B} 22$ steel with the following dimensions: $2.5 \mathrm{~mm}$ in diameter and $30 \mathrm{~mm}$ in length. For the measure of cooling rates, despites of thickness differences were used tridimensional extraction of heat (3D). Because, according to Machado [22], the error in calculating thermal flow using 3D models (case of $6 \mathrm{~mm}$ and $3 \mathrm{~mm}$ ) for regimes evaluated as 2.5D (case $1.5 \mathrm{~mm}$ ) is at most 20\%.

The welding of the specimens was performed with 6 different energies and three base plates, setting up an experimental design with 54 samples for analysis (three specimens for each weld). The pin (SAE 10B22 steel) used was the same for all plates.

\subsection{Analysis and testing}

The samples were cut transversely to the center of the pin, embedded, sanded and polished. The chemical attack was performed with a 3.5\% Nital solution. The chemical composition of the base materials was performed by a Shimadzu PDA-7000 Spectrometer. The images of the microstructures were captured through a light microscope. The hardness was verified through a Vickers microdurometer (HV) with loads used in the tests of 100 and 200 grams and time of 15 seconds. Hardness profiles were performed in the longitudinal section with respect to the pin at $0.03 \mathrm{~mm}$ intervals. The HAZ was analyzed using macrography and measured using Image software.

Thermal cycles and cooling rates were estimated from the Fourier Equation 3 [22,23].

$\frac{\delta T}{\delta t}=\alpha\left(\frac{\delta^{2} T}{\delta x^{2}}\right)+\left(\frac{\delta^{2} T}{\delta y^{2}}\right)+\left(\frac{\delta^{2} T}{\delta z^{2}}\right)$ 
$\alpha=\frac{k}{\rho c}$

where $T, \mathrm{t}, \alpha, k, \rho$ and $c$ and are respectively the temperature $\left({ }^{\circ} \mathrm{C}\right)$, the time $(\mathrm{s})$, the thermal diffusion $\left(\mathrm{m}^{2} / \mathrm{s}\right)$, the thermal conductivity $\left(\mathrm{W} \cdot \mathrm{m}^{-1} \cdot{ }^{\circ} \mathrm{C}^{-1}\right)$, the specific mass $\left(\mathrm{kg} \cdot \mathrm{m}^{-3}\right)$ and the specific heat $\left(\mathrm{J} \cdot \mathrm{kg}^{-1} .{ }^{\circ} \mathrm{C}^{-1}\right)$; and $x, y, z$ are the coordinates of the point considered $(\mathrm{m})$. The product $\rho c$ is usually termed "volumetric thermal capacity". This relationship is satisfied by Equation 5 , because in metals the transmission of the electric arc energy resulting from capacitive welding occurs in a short time (typically 0.5 to $1.5 \mathrm{~ms}$ ), which allows to consider it as coming from a heat source positioned on the surface of the material [22,23].

$\Delta T=T-T_{o}=\frac{Q}{4 \rho c(\pi t \alpha)^{\frac{3}{2}}} \cdot e^{\frac{\left(-R^{2}\right)}{4 t \alpha}}$

$R=\sqrt{x^{2}+y^{2}+z^{2}}$

where $T, T_{0}, Q$, e $R$ are, respectively, the temperature of the point of interest at a given time point $\left({ }^{\circ} \mathrm{C}\right)$, the preheating temperature $\left({ }^{\circ} \mathrm{C}\right)$, the amount of heat $(\mathrm{J})$ and the position of the point of interest in the part $(\mathrm{m})$. By deriving Equation 5 in relation to time, the cooling rates are obtained in the different relative positions, according to Equation 7 , without preheating temperature the welding was performed at room temperature [22].

$\frac{\delta T}{\delta t}=\frac{T}{t}\left(\frac{R^{2} T}{4 t \alpha}-\frac{3}{2}\right)$

The physical coefficients of the material must be known in order to solve Equations 5 and 7. As they practically do not vary among the steels used, we have opted for those values generally adopted for carbon steels [22], that is, $\rho c=4.5 \cdot 10^{6} \mathrm{~J} \cdot \mathrm{m}^{-3.0} \mathrm{C}^{-1}$ and $\alpha=9.1 \cdot 10^{-6} \mathrm{~m}^{2} \cdot \mathrm{s}^{-1}$, with melting temperature equal to $1530{ }^{\circ} \mathrm{C}$. Although these physical coefficients change as a function of temperature, these values provide useful estimates for various welding engineering applications.

For the determination of the arc welding and extinction times, a data acquisition system formed by a voltage divider, an acquisition board (NI USB 6009), software and computer were used. The acquisition rate used was $48 \mathrm{kHz}$. The average times of electric arc did not change in relation to the types of materials, but they changed in relation to the different energies. The mean electric arc times for the energies of $64 \mathrm{~J}, 128 \mathrm{~J}, 192 \mathrm{~J}, 256 \mathrm{~J}, 320 \mathrm{~J}$ and $384 \mathrm{~J}$ were, respectively, $0.27 \mathrm{~ms}, 0.54 \mathrm{~ms}, 0.83 \mathrm{~ms}$, $1.03 \mathrm{~ms}, 1.32 \mathrm{~ms}$ and $1.55 \mathrm{~ms}$, according to the short time condition for the use of Equation 5 and consequently Equation 7 .

\section{Results and Discussion}

The results are organized in relation to the three types of materials used for welding, in which analyses of chemical composition, microstructure and hardness of the formed phases are presented.

All materials (SAE 1045, DOMEX 700MC and DOCOL DP1000) were joined with a SAE $10 \mathrm{~B} 22$ material pin and the chemical composition is shown in Table 1.

Table 1. Chemical composition of SAE 10B22 steel [24].

\begin{tabular}{cccccccccccc}
\hline $\mathbf{C} \%$ & Si\% & Mn\% & P\% & Ni\% & Cr\% & Mo\% & Al\% & Ti\% & B\% & N\% \\
\hline 0.21 & 0.23 & 1.12 & 0.013 & 0.12 & 0.16 & 0.02 & 0.03 & 0.043 & 0.003 & 0.0047 \\
\hline
\end{tabular}

\subsection{Characterization of SAE 1045 steel}

Table 2 shows the values found for the chemical composition of the SAE 1045 steel sample.

Table 2. Chemical composition of SAE 1045 steel sample.

\begin{tabular}{cccccccccc}
\hline C\% & Si\% & Mn\% & P\% & S\% & Ni\% & Cr\% & Mo\% & Cu\% \\
0.45175 & 0.17454 & 0.67728 & 0.00893 & 0.00553 & 0.01139 & 0.01474 & 0.00168 & 0.00251 \\
\hline Co\% & Al\% & Pb\% & W\% & Ti\% & V\% & B\% & Nb\% & Fe\% \\
\hline 0.00407 & 0.08140 & --- & -- & 0.00292 & 0.00468 & 0.00052 & 0.00085 & 98.557 \\
\hline
\end{tabular}


Through the results of chemical composition, the carbon equivalent was calculated, using Equation 1 . The calculated carbon equivalent for the SAE 1045 steel sample is equal to 0.59 . The microstructure found in Figure $3 a$, for the characterization of SAE 1045 base steel, is composed of ferrite (F) and perlite (P). The average hardness of the found base material is approximately 196 HV "Vickers Hardness ".

Figure 4 shows the micrograph of the welded joint and regions of the weld to test specimens welded with SAE 1045 carbon steel with $64 \mathrm{~J}$ of energy. Other test specimen images that were taken indicate that, regardless of the energy, the change in the microstructure had little variation in the average energy levels selected for the experimental welding.

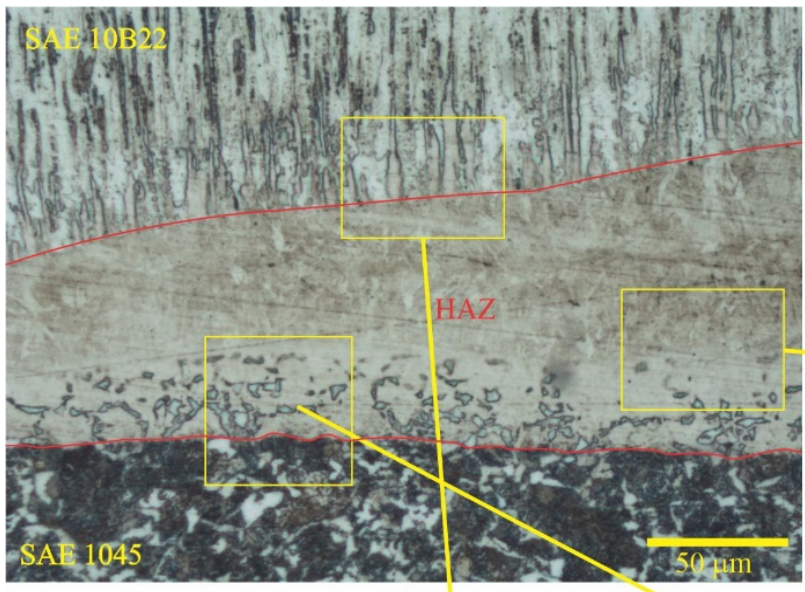

(a)

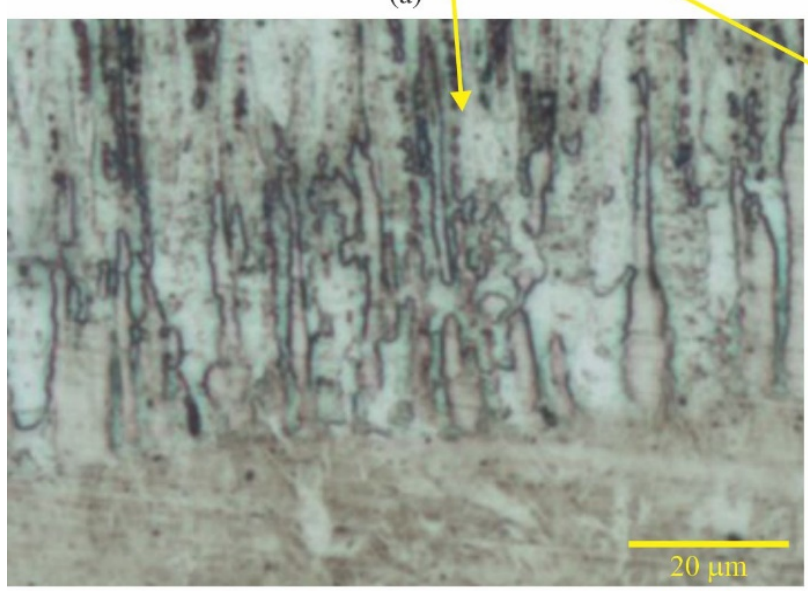

(c)

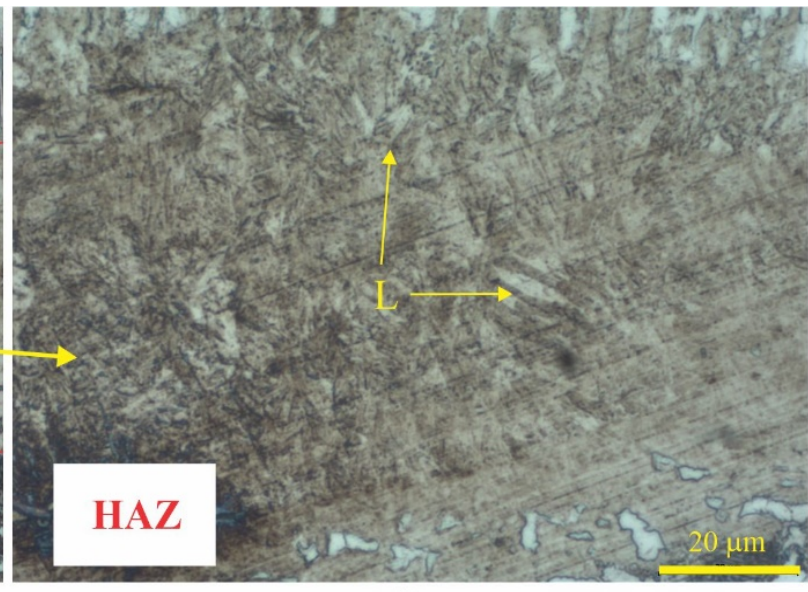

(b)

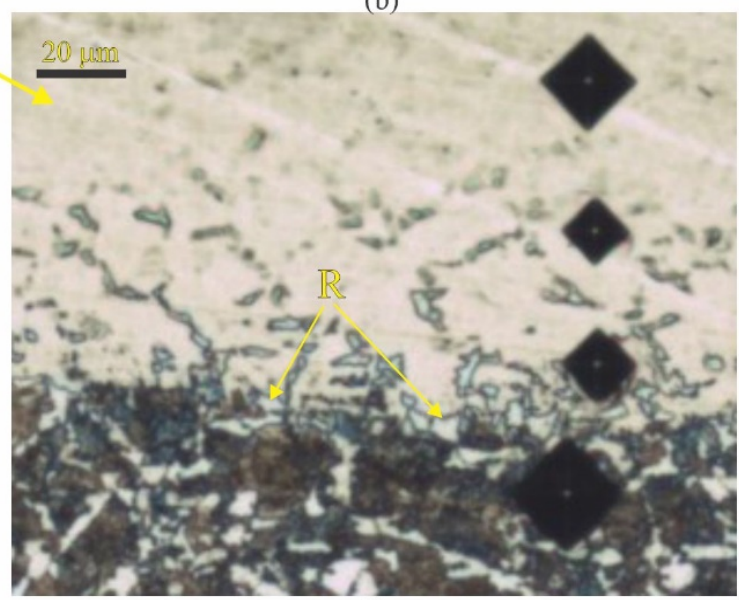

(d)

Figure 4. SAE 1045 steel and SAE 10B22 steel joined with $64 \mathrm{~J}$ of energy: (a) weld joint microstructure with SAE 1045 steel and SAE $10 B 22$ pin; (b) micrograph of the HAZ, showing the lamellae (L) formed by martensite; (c) SAE 10B22 pin and HAZ interface; (d) SAE 1045 steel and $H A Z$ interface with the indication of partially transformed structure $(R)$.

The value of 0.59 for the carbon equivalent of the SAE 1045 steel, when subjected to capacitive discharge welding, considering the high cooling rate in the welded region, generate a tendency of brittle welded joint. The brittleness of the welded joint is due, most likely, to the formation of the micro constituent martensite in the region affected by the heat of the weld, as shown in Figure $4 \mathrm{~b}$ by the yellow arrows (and the letter $\mathrm{L}$ ), where the lamellae that can characterize the mentioned microstructure are seen. It is still possible to visualize some aspects of the partially transformed structure, that is, the remaining structure of the base metal is indicated in Figure $4 \mathrm{~d}$ by the letter $\mathrm{R}$, with yellow arrows pointed at these structures. According TWI (The Welding Institute), the HAZ can be broken down into the grain coarsened zone (closest to the heated area), the grain refined zone, the partially transformed (intercritical heated) zone and the tempered zone. The partially transformed zone it's also called by Kou [25] as the partial grain-refining region is subjected to a peak temperature just above the effective lower critical temperature. The prior pearlite colonies transform to austenite and expand slightly into the prior ferrite colonies upon heating to above AC1 (start temperature of austenite formation) and then decompose into extremely fine grains of pearlite and ferrite during cooling. The distribution of pearlite and ferrite is not exactly uniform because the diffusion time for carbon is limited under the high heating rate during welding and the resultant austenite is not homogeneous $[25,26]$. These structures are characteristic of LASER surface treatment processes, studies $[10,27,28]$ have a similar structure, probably due to the high cooling rate, but also due to the high heating rate 
characteristic of the capacitive welding process [21]. Therefore, there is no time for the ferritic structure to solubilize while maintaining the original structure, as the high cooling rate does not affect the formation of this structure to form a metastable phase.

Phases formed in the samples welded with the SAE 1045 steel can be visualized in Figures $4 \mathrm{~b}$ and $\mathrm{d}$. The microstructure of the pin unaltered by the heat of the weld is shown in Figure 3d, used in the welding of the specimens. It consists of ferrite (light part - F) and perlite (dark part), with predominance of ferrite due to the low content of carbon content of this material. Ferrite is the micro-constituent with the lowest level of hardness. In Figure 3a the base metal is indicated. As it is expected from a SAE 1045 steel, it is presented in ferrite (white parts) and perlite (dark parts). The HAZ presents typical and expected characteristics for this welding process, that is, the microstructure is possibly composed of martensite lamellae (L). The obtained microstructural characteristics are equivalent for the samples of the 6 average levels of welding energy.

The thermal flux was obtained via Equation 5 for each energy level. The result was obtained in graph form, according to

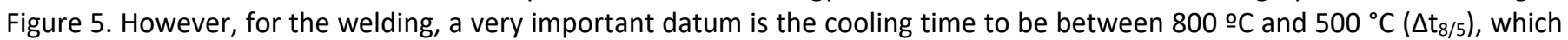
are critical values for phase transformations in steels, in general. The way $\Delta t_{8 / 5}$ is found is shown in Figure 5 , in which only the cooling time for the energy level of $64 \mathrm{~J}$ is shown.

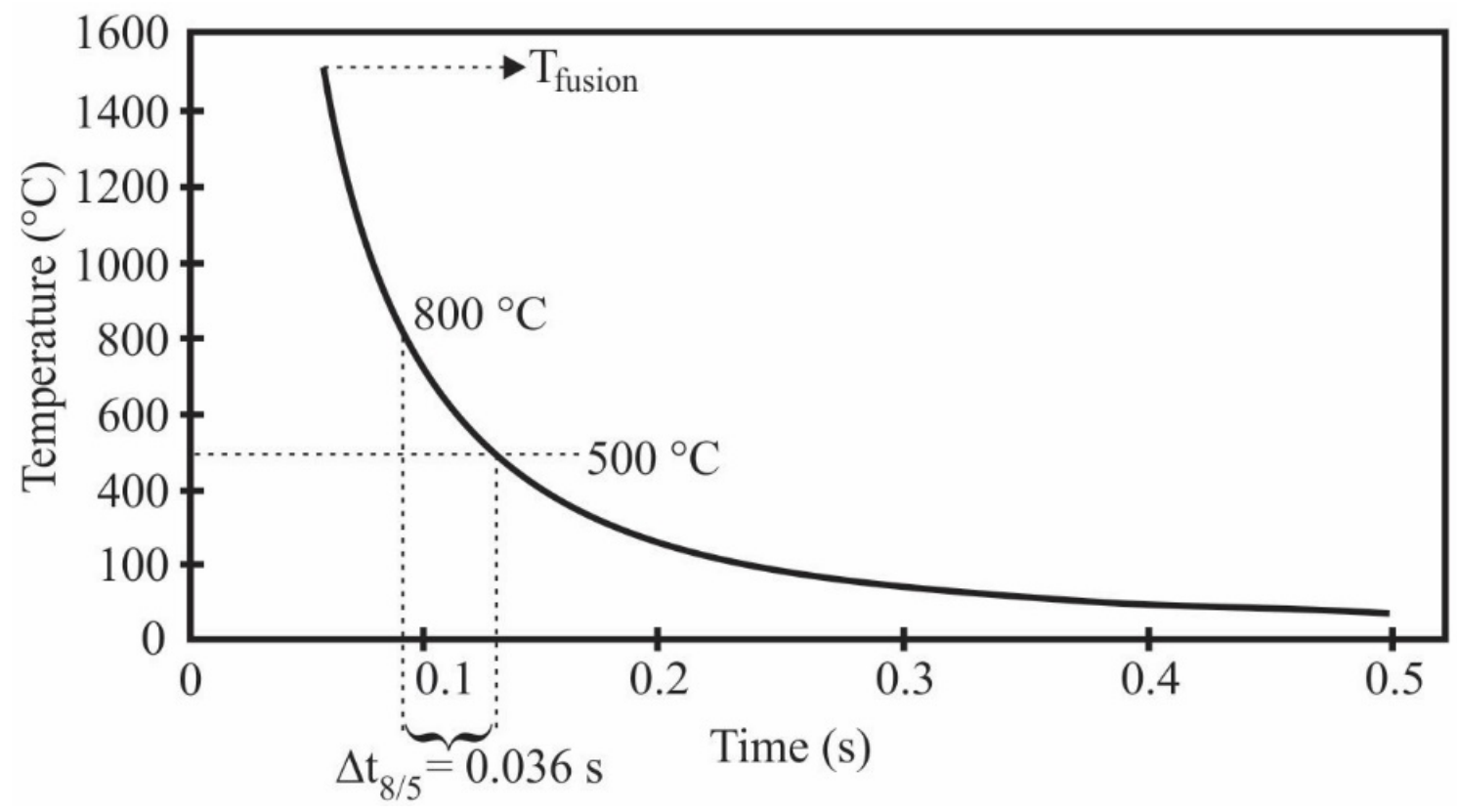

Figure 5. Cooling time at a distance of $0.5 \mathrm{~mm}$ from the heat source for $64 \mathrm{~J}$ of energy. [mod 18]

As indicated in Figure 5, the critical cooling time for welding was $0.036 \mathrm{~s}$ from $800{ }^{\circ} \mathrm{C}$ to $500{ }^{\circ} \mathrm{C}$. The same was performed for all the energy levels used in this work, for SAE 1045 steel. The values of $\Delta t_{8 / 5}$ and the maximum hardness values for all energy levels used are shown in Table 3, indicating the energy used, the maximum hardness value and the cooling time from $800{ }^{\circ} \mathrm{C}$ to $500{ }^{\circ} \mathrm{C}\left(\Delta \mathrm{t}_{8 / 5}\right)$.

Hardness profiles were performed in order to find the highest hardness value to welding with SAE 1045 steel, as shown in Figure 6.

The maximum hardness values in the HAZ region showed differences of the order of 820.4 to 641.7 HV characterizing martensite values, varying, most likely, by the small extent of HAZ, of the materials that have a higher cooling rate, that should have higher hardness values, presented the measurement of hardness, probably due to the heating time, the greater the energy the longer the time for the structure to solubilize, thus the cooling rate (which remains high for martensitic formation, for all energies, this is certified through the CCT diagrams of each material) achieves be more effective when compared to the material that took less time to solubilize the material. Equations 5 and 6 show that the reach (R) of the thermal flow depends directly on the energy applied in the welding $(Q)$, this indicates that with greater energy there is a greater thermally affected region. This means that the austenitic region will be larger the greater the energy due to the high heating rates, characteristics of the capacitive discharge welding process. With this it is possible to understand that a higher welding energy causes a larger HAZ to occur.

What corroborates this explanation is the fact that the hardness profile of the highest energies (384 and $320 \mathrm{~J}$ ) presented a greater extension of $\mathrm{HAZ}$, making its separation between the other regions clearer. 


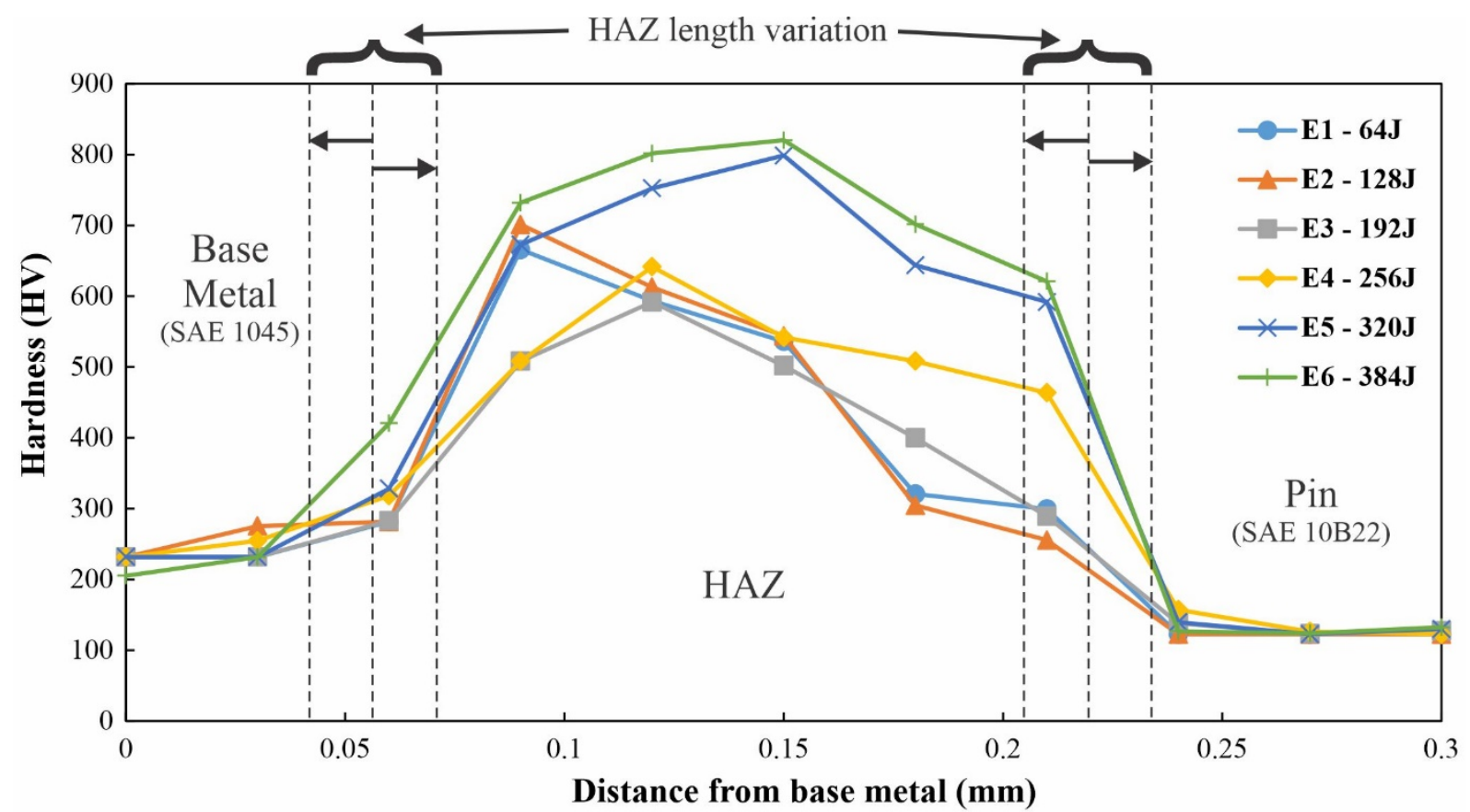

Figure 6. Hardness profile of welded 1045 steel samples for the different energies and spaced indentations of $0.03 \mathrm{~mm}$.

Table 3 lists the energy level, with the maximum hardness value, HAZ dimension and the cooling time from $800{ }^{\circ} \mathrm{C}$ to $500{ }^{\circ} \mathrm{C}$.

Table 3. Energy levels in relation to maximum hardness values and cooling time $\left(\Delta \mathrm{t}_{8 / 5}\right)$

\begin{tabular}{|c|c|c|c|}
\hline Energy level (J) & $\begin{array}{c}\text { Maximum hardness values } \\
\text { (HV) }\end{array}$ & HAZ $\left(\mathrm{mm}^{2}\right)$ & $\begin{array}{l}\Delta \mathrm{t}_{8 / 5}-\text { Cooling time from } 800 \\
{ }^{\circ} \mathrm{C} \text { to } 500{ }^{\circ} \mathrm{C}(\mathrm{s})\end{array}$ \\
\hline 64 & 665.9 & $0.101 \pm 0.005$ & 0.036 \\
\hline 128 & 701.1 & $0.111 \pm 0.004$ & 0.057 \\
\hline 192 & 591.9 & $0.123 \pm 0.003$ & 0.075 \\
\hline 256 & 641.7 & $0.146 \pm 0.004$ & 0.087 \\
\hline 320 & 798.7 & $0.165 \pm 0.004$ & 0.101 \\
\hline 384 & 820.4 & $0.173 \pm 0.005$ & 0.116 \\
\hline
\end{tabular}

The samples tested for SAE 1045 steel presented high values of hardness in the HAZ, the equivalent carbon content of 0.59 corroborates this fact. The mean values of hardness in the MB and in the pin (SAE 10B22) in positions unaltered by the heat of the weld, were of $250 \mathrm{HV}$ and $100 \mathrm{HV}$, respectively. These values are in accordance with characteristic result of the ferritic microstructure of these steels.

The hardness values, located in the HAZ region, are typical of the generated martensitic microstructure. The average energy of $384 \mathrm{~J}$ reached higher value in the HAZ, arriving at $820.4 \mathrm{HV}$. In general, all the average energies reached values that were superior to $500 \mathrm{HV}$ in the HAZ. The HAZ extension formed between the MB and the pin material was, on average, $0.10 \mathrm{~mm}$. Due to SAE 1045 steel having a heterogeneous structure (characterized by Figure 3a), the verified maximum values of hardness were also heterogeneous. This is most likely due to the rapid discharge of heat, which does not allow a homogeneity in the structure when the austenitization temperature is reached. With the rapid cooling, the non-homogeneous structure will have a higher hardness value where the structure has a higher carbon equivalent level. Consequently, where the structure has lower carbon equivalent values, it will have a lower hardness value.

\subsection{Characterization of Domex 700MC steel}

The results of the chemical composition found for the DOMEX 700MC steel sample are in accordance with the limits established by the manufacturer SSAB and DIN EN 10149-2 of a similar material $[17,29]$. When compared to 1045 steel, the low carbon content found in this material is evident. The values found for the chemical composition of the DOMEX 700MC steel sample can be visualized in Table 4.

The calculation of the equivalent carbon for the analyzed sample of the DOMEX 700MC steel was approximately 0.37, which is a lower value than the EC for the SAE 1045 steel sample. 
Table 4. Chemical composition of the DOMEX 700MC steel sample.

\begin{tabular}{cccccccccc}
\hline $\mathbf{C} \%$ & $\mathrm{Si} \%$ & $\mathrm{Mn} \%$ & $\mathrm{P} \%$ & $\mathrm{~S} \%$ & $\mathrm{Ni} \%$ & $\mathrm{Cr} \%$ & $\mathrm{Mo} \%$ & $\mathrm{Cu} \%$ \\
0.03503 & 0.04728 & 1.8253 & 0.00808 & 0.00389 & 0.03739 & 0.04633 & 0.00568 & 0.01194 \\
\hline $\mathrm{Co} \%$ & $\mathrm{Al} \%$ & $\mathrm{~Pb} \%$ & $\mathrm{Ti} \%$ & $\mathrm{~V} \%$ & $\mathrm{~B} \%$ & $\mathrm{Nb} \%$ & $\mathrm{Fe} \%$ & $\mathrm{EC} \%$ \\
\hline 0.02146 & 0.05283 & --- & 0.10275 & 0.02962 & 0.00074 & 0.06096 & 97.711 & 0.37 \\
\hline
\end{tabular}

The microstructure found in the DOMEX 700MC base steel is typical of low mechanical strength, with low carbon level and high manganese level. The microstructure is formed by ferrite, perlite and martensite. The average hardness is $302 \mathrm{HV}$ (Vickers hardness), a relatively high value when compared to SAE 1045 carbon steel. Figure 7 shows the microstructure of the welded joint between the SAE 10B22 pin and the DOMEX 700MC steel with $64 \mathrm{~J}$ energy, similar to that presented for the welded joint of the SAE 1045 steel.

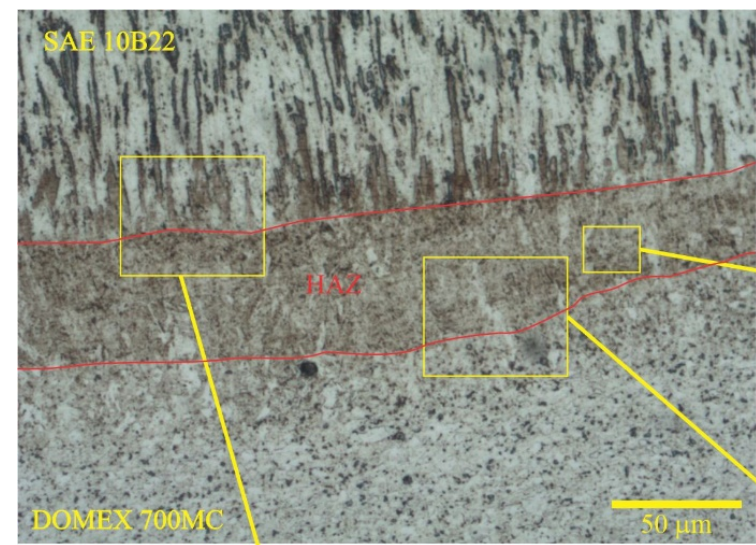

(a)

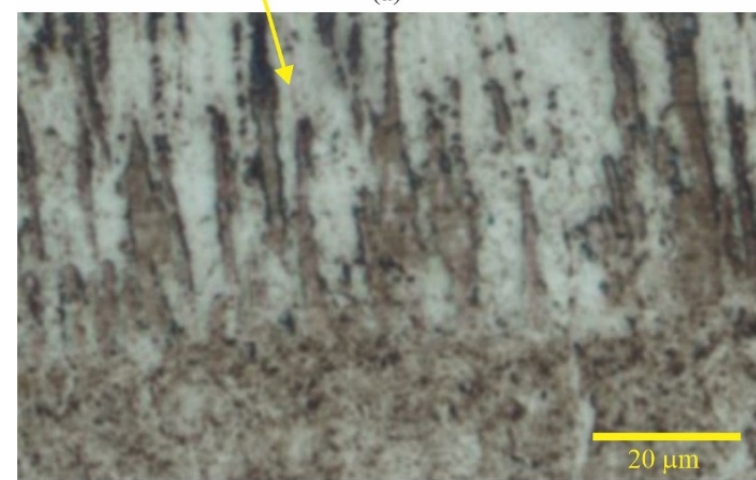

(c)

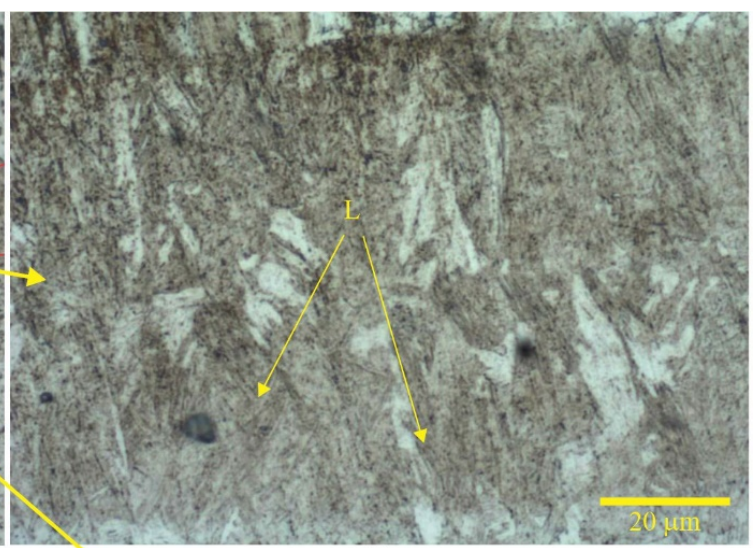

(b)

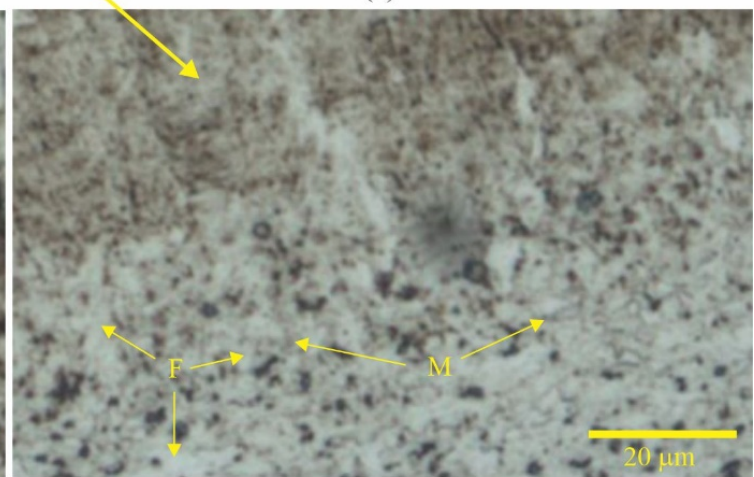

(d)

Figure 7. (a) Microstructure of the welded joint between the DOMEX 700MC steel and the SAE $10 B 22$ pin; (b) Micrograph of the HAZ showing the microstructure, evidencing martensite lamellae (L); (c) SAE $10 B 22$ pin and HAZ interface; (d) metal base and HAZ interface microstructure, showing ferrite $(F)$, perlite $(P)$ and martensite $(M)$.

Microstructure of DOMEX 700MC steel (Figure 3b), unaltered by heat, is typical of low alloy and low carbon steel, formed by ferrite ((F) matrix), perlite (dark points) and martensite ((M) lamellae like needles). The high energy released by the process, aligned with the rapid application of time in the order of milliseconds and the high cooling speed, contribute to the formation of martensite in the HAZ range, as can be seen in the Figure $7 \mathrm{~b}$.

The DOMEX 700MC base material has low level alloying elements, causing perlite formation in structures with a low content for carbon of $0.035 \%$, which means a higher toughness compared to carbon steel. When the capacitive welding process for this MB is applied, there is the formation of martensite, but with less brittle and more tenacious, with a lower hardness value, which are factors that are also interconnected with the lowest value of the carbon equivalent found for the DOMEX 700MC, when compared to steel SAE 1045.

The results obtained for the maximum hardness of the samples welded with different levels of average welding energy were obtained in an analogous way to SAE 1045 steel. The cooling time was also obtained in the same way as shown in Figure 5. The results can be seen in Table 5 , which shows the energy values related to the maximum hardness value and the cooling time $\left(\Delta \mathrm{t}_{8 / 5}\right)$. 
Table 5. Energy levels in relation to maximum hardness values and cooling time $\left(\Delta t_{8 / 5}\right)$.

\begin{tabular}{|c|c|c|c|}
\hline Energy Level (J) & Maximum hardness values (HV) & $\mathrm{HAZ}\left(\mathrm{mm}^{2}\right)$ & $\begin{array}{l}\Delta t_{8 / 5}-\text { Cooling time from } 800^{\circ} \mathrm{C} \\
\text { to } 500^{\circ} \mathrm{C}(\mathrm{s})\end{array}$ \\
\hline 64 & 441 & $0.068 \pm 0.003$ & 0.036 \\
\hline 128 & 463 & $0.072 \pm 0.002$ & 0.057 \\
\hline 192 & 473 & $0.097 \pm 0.006$ & 0.075 \\
\hline 256 & 511 & $0.109 \pm 0.004$ & 0.087 \\
\hline 320 & 441 & $0.127 \pm 0.006$ & 0.101 \\
\hline 384 & 487 & $0.166 \pm 0.003$ & 0.116 \\
\hline
\end{tabular}

Hardness profiles were performed in order to find the highest hardness value to welding with DOMEX 700MC steel, as shown in Figure 8.

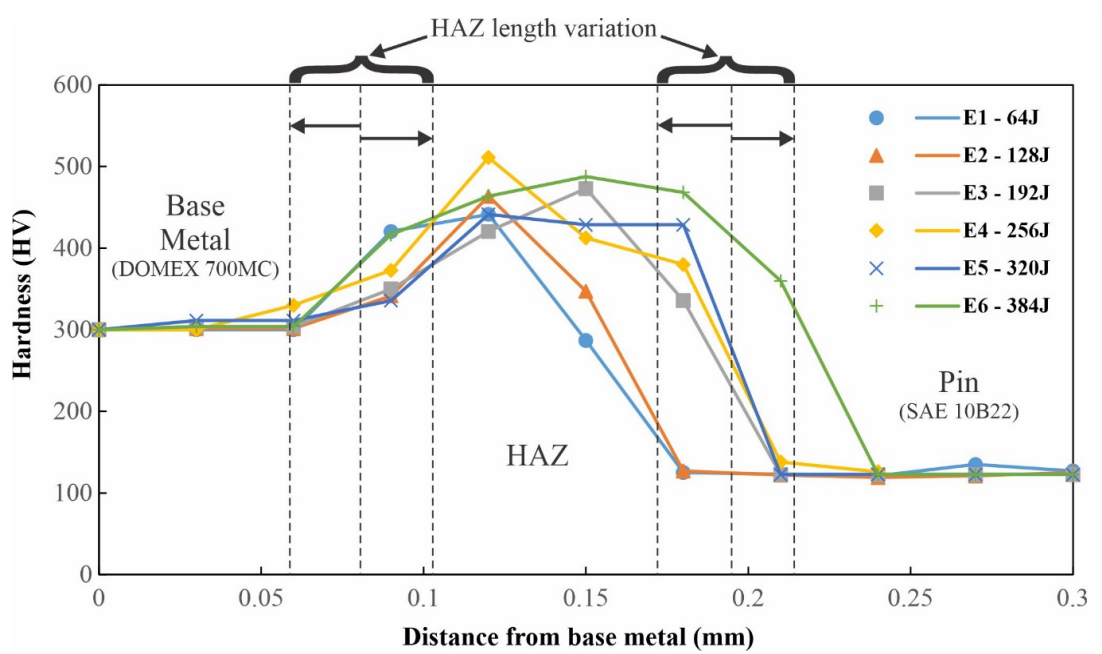

Figure 8. Hardness profile of welded DOMEX 700MC steel samples for the different energies and spaced indentations of $0.03 \mathrm{~mm}$.

Figure 8 shows the extent of the HAZ and the hardness profile values. The extension of HAZ for DOMEX 700MC steel is shorter than that of SAE 1045 steel. It is also clear, with the help of Table 5, that the difference in the area of HAZ for each energy value is greater when compared to the area of each energy for SAE 1045 steel. This may be a consequence of the greater homogeneity of the structure of each material. In steel 1045 the heterogeneity is more evident because in Figure $4 \mathrm{~d}$ the partially transformed zone is shown, which is not characterized with the same magnification amplitudes in the microscope, Figure 7d, for DOMEX 700MC steel. The homogeneity of Steels DOMEX and DOCOL in comparison of steel SAE 1045 is realized in Figure 3, where the magnification of 3(a) is double times mayor to adjust the structures of tree steels in the dimension similar.

As previously mentioned, there was no evidence of a fusion zone, probably due to its small size and the methodology applied in the work. However, it apparently does not affect the result when comparing the steel plates in question at work. If the objective of the work was to analyze the fusion zone, the welding energy should be increased.

It can be noticed that, for the six levels of average energy, there was an increase of the hardness in the martensitic region of the HAZ. However, it is relevant that the level of hardness found in the HAZ of the DOMEX 700MC samples is lower than the hardness level of the SAE 1045 steel in the HAZ formation, which is related to the solder functionality. A lower hardness value can be considered positive if this set is submitted to dynamic efforts. The lowest level of hardness in relation to 1045 steel is due to the percentage of carbon, carbon equivalent and the alloying elements of DOMEX 700MC steel, a fact that is cited by the study of Lisiecka and Lisiecki [17], for a similar steel analysis.

The average energies of $192 \mathrm{~J}$ and $256 \mathrm{~J}$ reached the highest values of hardness in the HAZ, respectively, $487 \mathrm{HV}$ and $511 \mathrm{HV}$. In general, all average welding energies reached values higher than $400 \mathrm{HV}$ in the HAZ. In relation to the extent of the HAZ formed between the MB and the material of the pin, the average energies of $192 \mathrm{~J}$ and $256 \mathrm{~J}$ reached greater extension. This is, probably, due to the heating time, the greater the energy the longer the time for the structure to solubilize, thus the cooling rate (which remains high for martensitic formation, for all energies) manages to be more effective when compared to the material that had less time to solubilize the material.

There is also a small variation between the maximum hardness values. This is perhaps due to the homogeneity of the microstructure of the DOMEX 700MC steel, as shown in Figure $3 \mathrm{~b}$. 


\subsection{Characterization of DOCOL DP 1000 steel}

The results of the chemical composition found for the DOCOLDP 1000 steel sample are in accordance with the limits established by the manufacturer SSAB [30]. The sample has a low level of carbon and other alloying elements. Table 6 shows the values found for the chemical composition of the DOCOL DP 1000 steel sample.

Table 6. Chemical composition of DOCOL DP 1000 steel sample.

\begin{tabular}{cccccccccc}
\hline $\mathrm{C} \%$ & $\mathrm{Si} \%$ & $\mathrm{Mn} \%$ & $\mathrm{P} \%$ & $\mathrm{~S} \%$ & $\mathrm{Ni} \%$ & $\mathrm{Cr} \%$ & $\mathrm{Mo} \%$ & $\mathrm{Cu} \%$ \\
0.12752 & 0.52055 & 1.4517 & 0.00794 & 0.00451 & 0.03673 & 0.03156 & 0.00568 & 0.01956 \\
\hline $\mathrm{Co} \%$ & $\mathrm{Al} \%$ & $\mathrm{~Pb} \%$ & $\mathrm{Ti} \%$ & V\% & $\mathrm{B} \%$ & $\mathrm{Nb} \%$ & $\mathrm{Fe} \%$ & $\mathrm{EC} \%$ \\
\hline 0.02892 & 0.07760 & --- & 0.00605 & 0.01957 & 0.00065 & 0.02624 & 97.635 & 0.47 \\
\hline
\end{tabular}

From the results found for the chemical composition, the carbon equivalent value for the DOCOL DP 1000 steel sample is approximately 0.47 .

The microstructure found for the DOCOL DP 1000 base material sample consists mainly of ferrite (F) and martensite (M) (Figure 3c), which is typical of materials with biphasic microstructure. The average hardness found in DOCOL DP 1000 steel is $335 \mathrm{HV}$, a relatively high value, but justified by the presence of martensite. Figure 9 shows the microstructure of the welded joint between the SAE 10B22 pin and the DOCOL DP 1000 steel with 64 J energy.

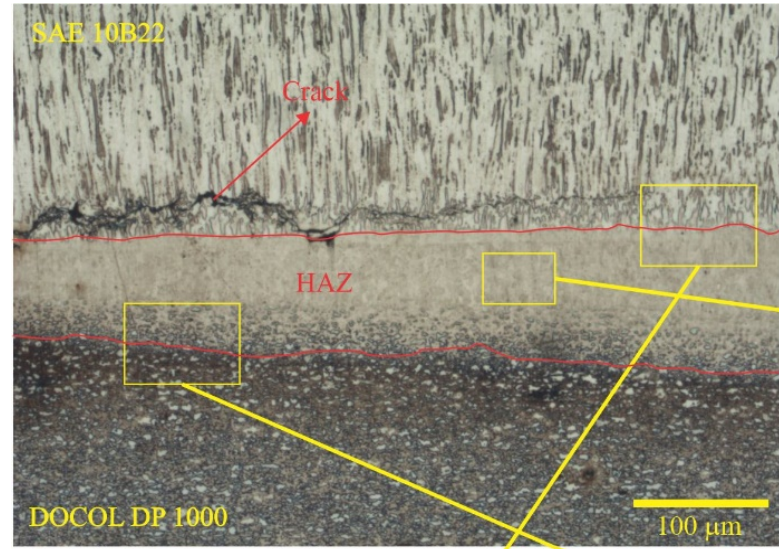

(a)

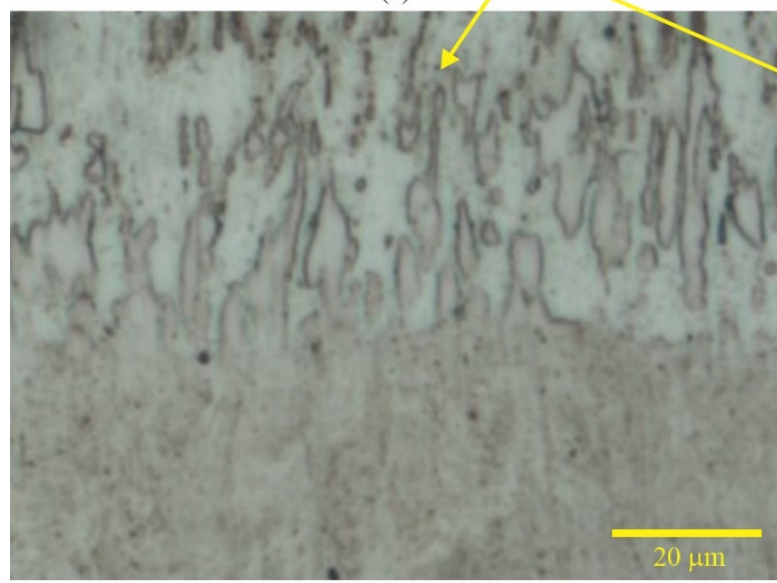

(c)

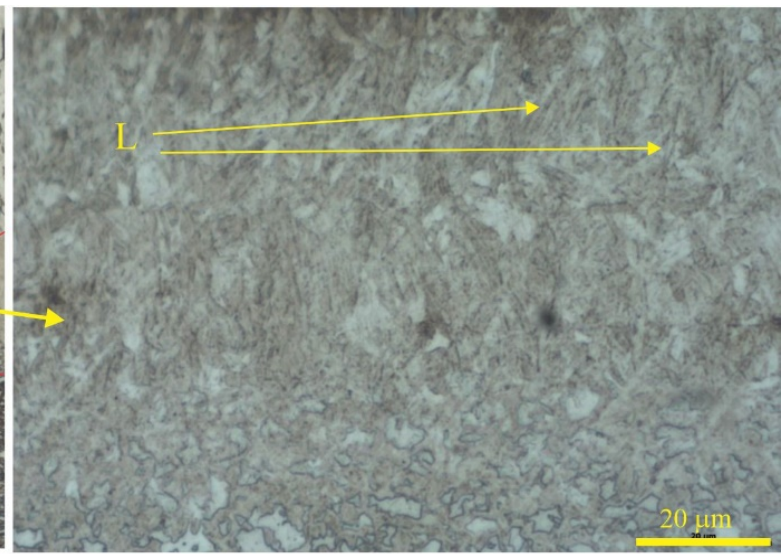

(b)

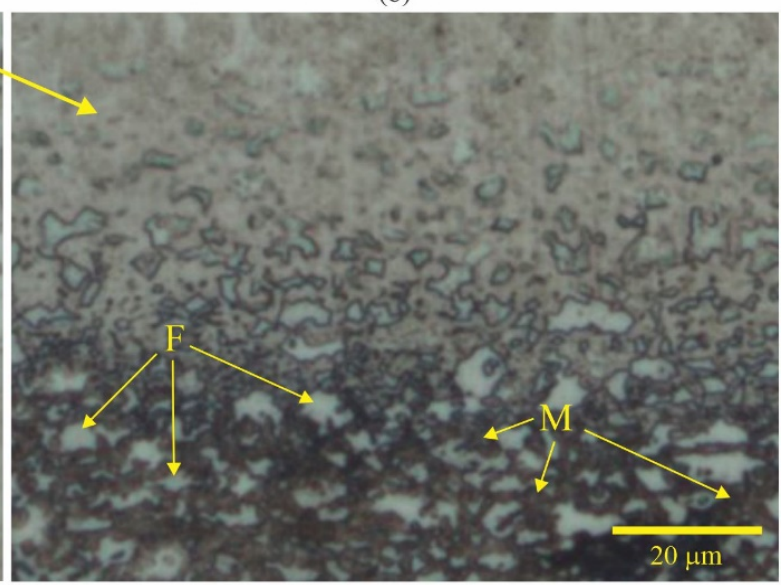

(d)

Figure 9. (a) Microstructure of the welded joint between the DOCOL DP 1000 steel and SAE 10B22 pin; (b) micrograph of HAZ showing the microstructure, evidencing martensite lamellae (L); (c) SAE 10B22 pin and HAZ interface; (d)) DOCOL DP 1000 base metal and HAZ interface microstructure showing ferrite $(F)$ and martensite $(M)$ characterizing the two phases (DP - Dual Phase) according to the manufacturer.

The phases formed in the samples welded with the base steel DOCOL DP 1000 were similar to the six different levels of average welding energy, i.e. in the HAZ region, formed by the capacitive discharge welding process, the microstructure consists of martensite. The value of 0.47 for the equivalent carbon, since it is considered a high value, is also a factor that contributes to the formation of martensite. In Figure $9 \mathrm{~b}$ is possible realize, probably, lamella of martensite, indicates by the letter " $\mathrm{L}$ ". In the 
bottom of Figure $9 \mathrm{~d}$ is the base metal and right up is a kind of partially transformed zone similar to what occurred in SAE 1045 steel (Figure 4d).

However, the characteristics found in HAZ for the DOCOL DP 1000 steel and for the DOMEX 700MC steel are similar. There is no increase in hardness in the HAZ of the DOCOL DP 1000 steel in relation to the DOMEX 700MC, and the two steels form martensite.

The results found for the maximum values of hardness and cooling time are shown in Table 7. The values were obtained in the same way as for the steels mentioned above, SAE 1045 and DOMEX 700MC steel.

Table 7. Energy levels in relation to maximum hardness values and cooling time $\left(\Delta t_{8 / 5}\right)$.

\begin{tabular}{cccc}
\hline Energy Level (J) & $\begin{array}{c}\text { Maximum hardness values } \\
\text { (HV) }\end{array}$ & $\begin{array}{c}\text { HAZ }\left(\mathbf{m m}^{2}\right) \\
\Delta 4\end{array} \quad 483$ & $\begin{array}{c}\Delta t_{8 / 5}-\text { Cooling time from } 800 \\
{ }^{\circ} \mathrm{C} \text { to } 500{ }^{\circ} \mathrm{C}(\mathrm{s})\end{array}$ \\
128 & 473 & $0.115 \pm 0.004$ & 0.036 \\
192 & 487 & $0.127 \pm 0.007$ & 0.057 \\
256 & 492 & $0.143 \pm 0.005$ & 0.075 \\
320 & 491 & $0.169 \pm 0.004$ & 0.087 \\
384 & 514 & $0.175 \pm 0.006$ & 0.101 \\
\hline
\end{tabular}

Hardness profiles were performed in order to find the highest hardness value to welding with DOCOL DP 1000 steel, as shown in Figure 10.

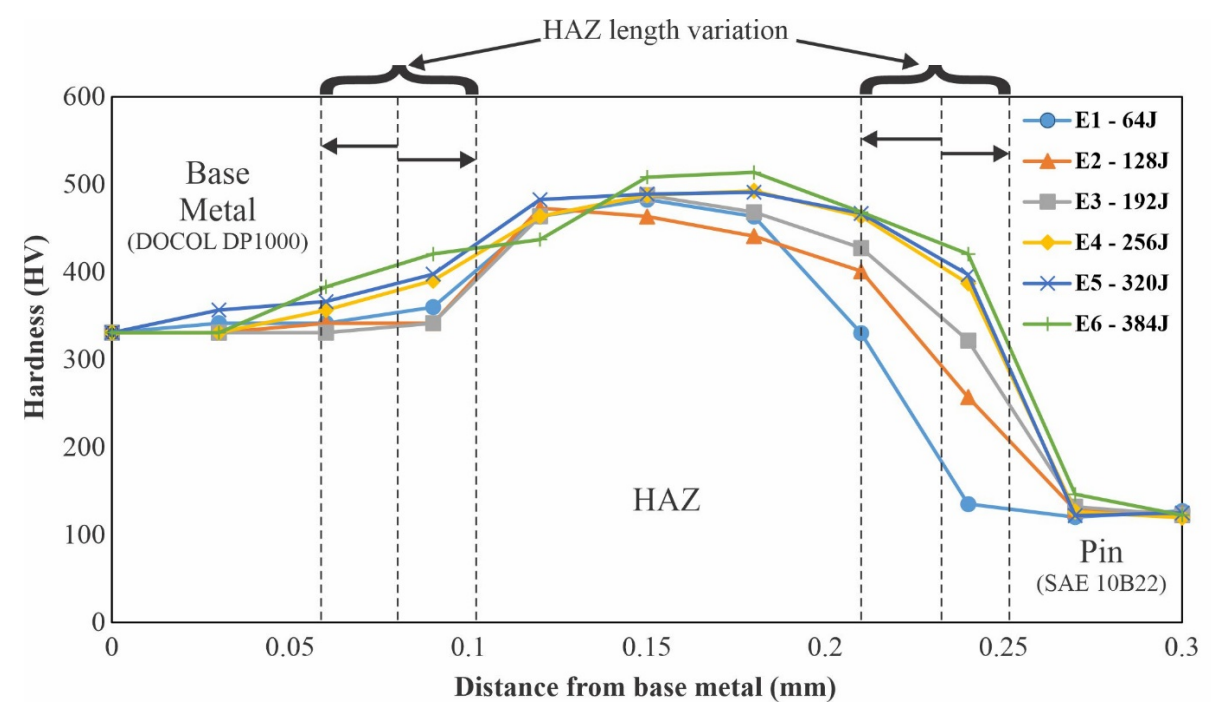

Figure 10. Hardness profile of welded DOCOL DP 1000 steel samples for the different energies and spaced indentations of $0.03 \mathrm{~mm}$.

Figure 10 shows the values of the hardness profile and the extent of the HAZ. With the exception of the border regions of $H A Z$, the hardness values are similar, which indicates a similar structure in the most central regions of HAZ, this probably occurs due to the technology used in the manufacture of the material that presents the material with a homogeneous structure, more homogeneous when compared to SAE 1045 steel, which presents obsolete manufacturing technology, when compared to DOCOL DP 1000 steel.

The hardness of the MB where it was not affected by the heat of the weld was $340.9 \mathrm{HV}$, and the hardness in the pin, also in the unaltered region, was $120 \mathrm{HV}$. The hardness of the MB DOCOL DP 1000 is the largest compared to the 1045 and DOMEX $700 \mathrm{MC}$ steels.

For the six levels of average energy, there was an increase in hardness in the martensitic region of the HAZ formed by the capacitive welding process. The level of hardness found in the HAZ of the DOCOL DP 1000 samples was lower than the hardness level of the 1045 steel and similar to the DOMEX 700MC steel.

In general, for the six medium energies applied in the welding tests, there was an increase in hardness in the HAZ region, with values higher than $400 \mathrm{HV}$. The average energy of $384 \mathrm{~J}$ reached a higher hardness value in the HAZ, with $514 \mathrm{HV}$. Similar to what happened with the DOMEX 700MC steel, there is little variation between the maximum hardness values. This is probably due to the homogeneity of the microstructure of the DOMEX 700MC steel. Both the DOMEX 700MC steel and the DOCOL DP 1000 steel have a greater homogeneity in their microstructure when compared to SAE 1045 steel. This is the result of the greater 
control and the greater technology in the manufacture of these steels and due to the heating time, the greater the energy the longer the time for the structure to solubilize, thus the cooling rate (which remains high for martensitic formation, for all energies) manages to be more effective when compared to the material that had less time to solubilize the material.

If the welded assemblies are subjected to dynamic stresses, it is not recommended to use steels with a carbon equivalent value above 0.30 or steels with a hardness above $286 \mathrm{HV}$, since the HAZ microstructure will be martensitic and the hardness will be high, which can lead to future cracks and failures in the welded joint. It can be noticed the lowest hardness level in the HAZ of DOMEX 700MC and DOCOL DP 1000 steels for all average welding energies compared to SAE 1045 steel.

Figure 11 shows the maximum hardness values, related to the steel used (and its equivalent carbon) and the welding energy applied in the process.

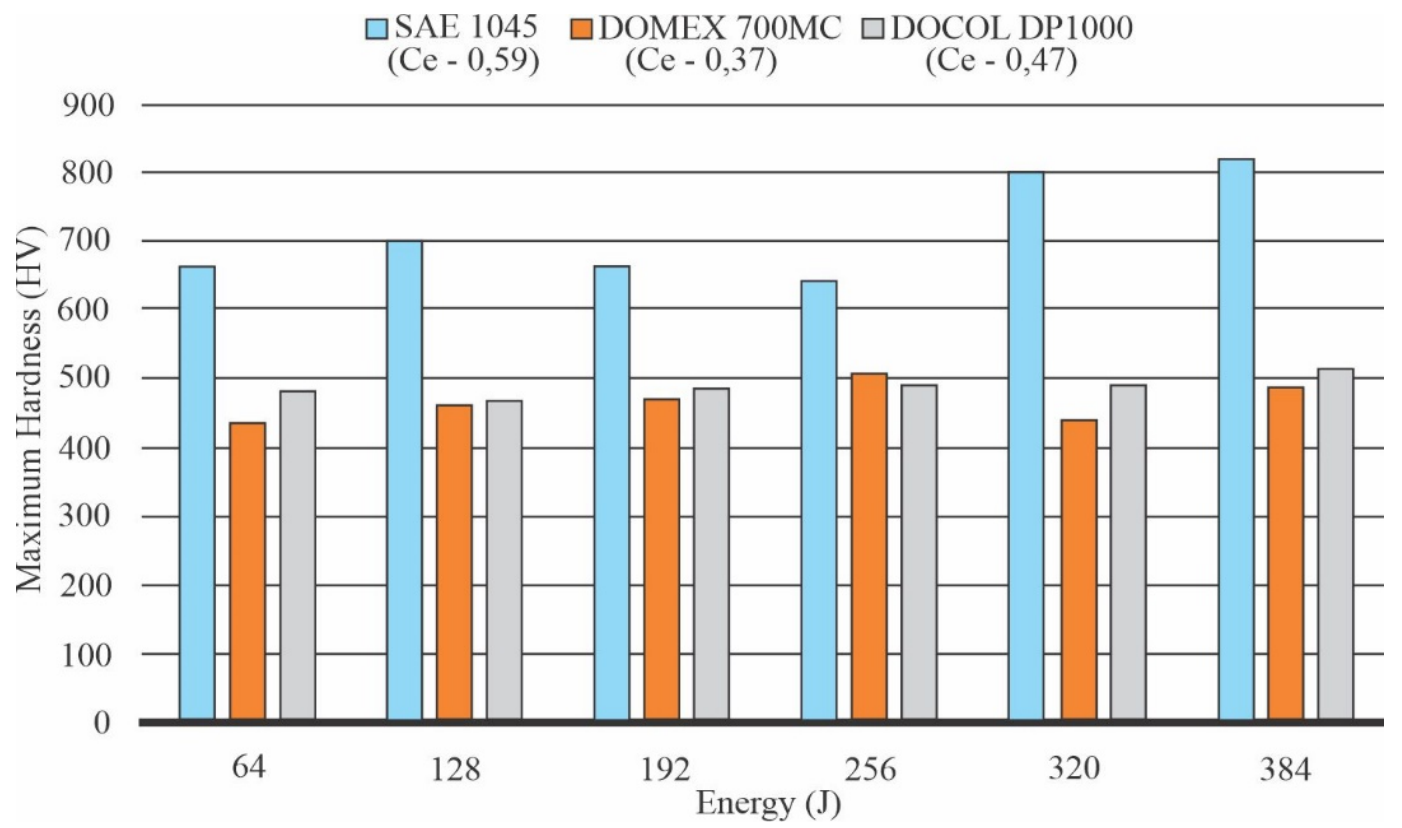

Figure 11. Maximum Hardness related to the energy used in the process and the material (and the Equivalent Carbon - Ce).

In Figure 11, it is possible to notice that a higher carbon equivalent value is related to higher hardness values and as already discussed in the work, the cooling rate values were sufficient to form a fragile structure, high hardness. That is the reason there is no expressive variation in the maximum hardness values with the energy values. The maximum hardness values in the energy of $256 \mathrm{~J}$ show a difference between DOMEX and DOCOL steels, this is probably related to a heterogeneity of material (all materials are heterogeneous) or to some simple verification error, it was not verified again, since the values are close, and it is not a very different value from those previously verified.

\section{Conclusions}

In this work, four different welded steels were characterized by the capacitive discharge welding process. The effect of the application of six levels of average welding energy was analyzed for the SAE 1045, DOMEX 700MC and DOCOL DP 1000 steels welded with SAE 10B22. From the results and discussions presented, the following has been concluded:

- Capacitive discharge welding process generates a HAZ of short extension, with a dimension that varies from tenths of a millimeter. In the welded test specimens, the extension of HAZ ranged from $0.068 \mathrm{~mm}$ to $0.189 \mathrm{~mm}$ for different energies and kind of steels. It was also observed that by increasing the welding energy the HAZ increased;

- As experienced, the process of welding by capacitive discharge applied in the welding of the test specimens caused the microstructural evolution in the HAZ region, that is, it formed martensite. The high cooling rate of the welded region added to the characteristics of the SAE 1045, DOMEX 700MC and DOCOL DP 1000 steels, where the three steels presented high values of the equivalent carbon, which collaborated to the formation of martensitic microstructure in the HAZ of all welded test specimens, and, consequently, a considerable increase of hardness in the HAZ region can be verified;

- The variation of the hardness values is related to the equivalent carbon value and the dimensions of the HAZ are related to the welding energy, the greater the energy, the greater the dimension. 


\section{Acknowledgements}

The author, R.T.L would like to thank Fundação Meridional and Coordenação de Aperfeiçoamento de Pessoal de Nível Superior (CAPES) for support.

\section{References}

[1] Gunning K, Stanley L, Humphrey H. inventor. Capacitive discharge welding saves time and improves results. United States patent US 8937263B2. 2016 Mar 25.

[2] Kren L, Reitz V. Basics of design engineering: fastening and joining. Machine Design. 2001;73(20):85.

[3] Fermo IR, Sakiyama RZ, Souza M, Andrade CMG. Equipamento automatizado de soldagem capacitiva para termopares. Soldagem e Inspeção. 2019;24:e2417. http://dx.doi.org/10.1590/0104-9224/si24.17.

[4] Cueman MK, Williamson R. Process model for percussion welding. Supplement to the Welding Journal. 1989;68(9): S349-S355.

[5] Chiozzi S, Dattoma V, Panella F, Panella F. Capacitor discharge welded bars of Inconel 718 and TiAl6V4 superalloys under fatigue. Materials \& Design. 2008;29(4):839-851. http://dx.doi.org/10.1016/j.matdes.2007.03.011.

[6] Paul BK, Thaneepakorn W. Effect of capacitor discharge welding on single-crystal metals. Journal of Manufacturing Processes, 2000;2(3):143-150

[7] Jianzhao W, Ohse P, Su W, Dilthey U. Impulse capacitor discharge welding of hollow structure made of nickel-base alloy. Tsinghua Science and Technology. 2007;12(4):453-458.

[8] Cavaliere P, Panella F, Panella F. Mechanical and microstructural behaviour of CMSX-4 Ni-based superalloy joined by capacitor discharge welding. Journal of Materials Processing Technology. 2007;183(2-3):297-300. http://dx.doi.org/10.1016/j.jmatprotec.2006.10.020.

[9] Dattoma V, Palano F, Panella FW. Mechanical and technological analysis of AISI 304 butt joints welded with capacitor discharge process. Materials \& Design. 2010;31(1):176-184. http://dx.doi.org/10.1016/j.matdes.2009.06.035.

[10] Verástegui RN, Machado IG. Análise microestrutural de pontos fundidos na superfície de aços por LASER. Soldagem \& Inspeção. 2007;13(1), 46-54.

[11] Gimenes L Jr, Tremonti MA. Soldagem de Pinos. 1995. [access 3 apr. 2020]. Available from: <http://www.asmtreinamentos.com.br/asm/downloads/solador/arquivo71.pdf

[12] Fusion Solutions. Capacitor discharge welding technical data. 2001. [access 25 apr. 2020]. Available from: http://cdfusion.com/doc/CDFS_White_Paper.PDF

[13] Tru-Weld. Capacitor Discharge Stud Welding Booklet. 2013. [access 23 apr. 2020]. Available from http://www.truweldstudwelding.com/CDStudBooklet.pdf

[14] American National Standards Institute. AWS C5.4. Recommended Practices for Stud Welding. Miami, FL: ANSI; 1993.

[15] Gliner RE. Welding of advanced high-strength sheet steels. Welding International. 2011;25(5):389-396. http://dx.doi.org/10.1080/09507116.2011.554234.

[16] American National Standards Institute. ANSI/AWS D1.1/D1.1M. Structural Welding Code --Steel. Miami, FL: ANSI; 2000.

[17] Lisiecka AK, Lisiecki A. LASER Welding of the New Grade of Advanced High Strength Steel DOMEX 960. Materials and Technology. 2017;51(2):199-204.

[18] Database of Steel Transformation Diagrams. AISI 1045 Steel. [access 31 ago. 2020]. Available from: http://www.steeldata.info/std/demo/data/5002.html

[19] Górka J, Ozgowicz A. Structure and properties of LASER-Beam-Welded joints of low-alloy high-strength steel DOCOL $1200 \mathrm{M}$ With a Martensitic Structure. Materials and Technology. 2018;52(2):189-193.

[20] Machado IG. Soldagem e técnicas conexas: processos. Porto Alegre: Ed. do Autor; 1996.

[21] Wilson RD, Woodyard JR, Devletian JH. Capacitor discharge welding: Analysis through ultrahigh-speed photography. Welding Research Supplement. 1993;71(Suppl.):101s-106s.

[22] Machado IG. Condução do Calor na Soldagem: fundamentos e aplicações. 1ạ ed. Porto Alegre: Imprensa Livre S.A.; 2000.

[23] Carslaw HS, Jaeger JC. Conduction of heat in solids. 2nd ed. Oxford, UK: Oxford University Press; 1960.

[24] Casarin SJ. Caracterização da temperabilidade de aço C-Mn microligado ao boro, através da dilatometria e curvas de transformações de fases por resfriamento contínuo [tese de doutorado]. São Carlos: EESC, USP; 1996. http://dx.doi.org/10.11606/T.88.1996.tde-29012010160947.

[25] Kou S. Welding metallurgy and weldability of high strength aluminum alloys. United States: Welding Research Council, 1986. 
[26] TWI. What is the heat affected zone (HAZ)? [Access 31 ago. 2020]. Avaliable from: https://www.twi-global.com/technicalknowledge/faqs/what-is-the-heat-affected-zone

[27] Li R, Jin Y, Li Z, Qi K. A comparative study of high-power diode laser and CO2 laser surface hardening of AISI 1045 Steel. Journal of Materials Engineering and Performance. 2014;23(9):3085-3091. http://dx.doi.org/10.1007/s11665-014-1146-x.

[28] Maharjan N, Zhou W, Zhou Y, Wu N. Laser Surface Hardening of AISI 1055 Steel in Water Submerged Condition. Surface Review and LettersVol. 2020;27(1):1950087. http://dx.doi.org/10.1142/S0218625X19500872.

[29] SSAB. STRENX ${ }^{\circledR}$, Performance Steel. 2020. [Access 31 ago. 2020]. Avaliable from: <https://www.ssab.com.br/products/brands/strenx/products/strenx-700-mc>

[30] SSAB. DOCOL ${ }^{\circledR}$, The Automotive Steel. 2020. [Access 31 ago. 2020]. Avaliable from: <https://www.ssab.com/products/brands/docol/products/docol-1000dp>. 